\title{
ASSESSING THE EFFECTIVENESS OF WATER AND SANITATION SECTOR GOVERNANCE NETWORKS IN DEVELOPING COUNTRIES: A POLICY ANALYSIS FRAMEWORK
}

\author{
RIGOBERTO E. ALVARADO \& LISA M. BORNSTEIN \\ School of Urban Planning, McGill University, Canada.
}

\begin{abstract}
In developing countries, water and sanitation services for rural and peri-urban areas often are provided by networks comprised of governmental and non-governmental actors. The resulting governance systems are rarely evaluated, in part because the methods to do so are complex and unclear. This paper builds on network governance theory to (a) propose a new framework for the assessment of the effectiveness of Water and Sanitation governance networks in developing countries and (b) apply it through field research in Honduras. Network theory suggests that, since the sum of the network is greater than its individual parts, the effectiveness of a network should be evaluated based on the performance of the overall network rather than that of its individual network actors. The proposed assessment framework starts with this premise and evaluates overall network effectiveness in the four stages of the policy process: policy development; policy decisions; implementation; and monitoring \& evaluation. For the case of Honduras, performance indicators were specified for each policy stage, and an assessment conducted of the overall network's performance. Key findings from the assessment relate to the importance of metagovernance coordination functions, dramatic expansion of services, and key gaps in network integration. The research, and the assessment framework, will be of interest to those concerned with the effective delivery of basic services, particularly to secondary cities of the developing world where, as in Honduras, governance network commonly provide services and data for assessment are not yet compiled.

Keywords: evaluation, network governance, performance indicators, policy cycle, water and sanitation, water boards, water quality, water supply.
\end{abstract}

\section{INTRODUCTION}

Governments and institutions worldwide provide water and sanitation services to the population through the traditional, formal government commitments and, increasingly, through networks and partnerships. These networks and partnerships may involve diverse actors - for example, international agencies, national regulatory bodies, non-governmental organizations (NGOs), municipal government and water boards (local resident associations) that work together to define policy, pool resources and deliver services (or other goods). Countries using a network and partnership approach have often seen the rapid expansion of water and sanitation facilities, especially in rural and sub-urban areas [1,2]. The challenge for evaluation, and the overall effectiveness of the water and sanitation sector, is that while assessment approaches are known and established for traditional service provision, they are lacking for network and partnership approaches [3].

The value of monitoring and evaluation is known. In the case of water and sanitation, evaluation can lead to better use of resources and better quality service, whether in terms of those reached, the service provided or equity outcomes [4]. Periodic evaluations by governments or civil society could likely accelerate and improve the effectiveness of service provision, including for the poorest members of society. Undertaking regular evaluations is essential for continuous performance improvement and for the most effective use of limited resources [5]. In the case of governance networks, assessment is complicated by the highly dynamic nature 
of the network itself and the involvement of multiple stakeholders, who have differing levels of power and influence, operate at multiple geographical scales and have different roles and engagement levels in the network.

Our research takes on this challenge, developing a new approach to the assessment of network governance. The approach is both theoretical-conceptual, drawing on existing literature on network governance to design an evaluation framework around the policy cycle, and empirical in that the specific performance indicators are tailored to a local context and the evaluation approach is tested within that context. Our case study setting is Tela, a mediumsize municipality on the northern coast of Honduras, where network governance in the water and sanitation sector (WSS) has risen over the past decade.

The development of an evaluation approach for WSS governance networks entailed five components: a review of literature on governance networks and their evaluation to develop the policy analysis framework (PAF); identification of the governance network for a case study municipality; distribution of resulting research tools to stakeholders in that network; analysis of those results to reach conclusions about the effectiveness of the network in the Municipality of Tela's WSS; and a meta-analysis of the usefulness of the PAF evaluation framework. The water and sanitation sector of the Municipality of Tela was selected as a case study because it was one of the first municipalities in Honduras to operate under the new water and sanitation framework law of 2003. A qualitative line of inquiry was used given the exploratory aspect of the research [6]. This article reports specifically on the development and application of this new policy analysis framework (PAF) to the assessment of the effectiveness of Water and Sanitation Sector, an approach targeted to the governance networks increasingly present in the sector in medium-sized municipalities of developing countries. The material is presented in five parts: this introduction, the theoretical and empirical foundations of an evaluation approach for governance networks, the application of the approach using context-specific performance indicators, application of the policy analysis framework, and concluding comments.

\section{THEORETICAL AND EMPIRICAL FOUNDATIONS}

Water and sanitation programs in developing countries are increasingly handled through a network mode of governance. As such, it becomes urgent to assess these networks. However, the evaluation of WSS governance networks is a complex task, in part because of the number of different stakeholders and also due to the multi-level nature of the task, the highly dynamic nature of the network, the potential for external influence, and the multiple perspectives from which one could design and launch legitimate assessments [7]. For example, evaluations can be initiated by international development organizations, central government institutions, municipalities, participating communities or external evaluators, each of whom may have their own criteria for effectiveness. Implicit in this statement is that assessments can be done from multiple perspectives; obviously, evaluating from all perspectives is not realistic or practical. The question thus arises of what can pragmatically be undertaken to assess effectiveness and decision making within the network context.

Appropriate theoretical-based methods for the assessment of governance networks were sought in the literature; the field is incomplete and highly fragmented. Moreover, it is not evident how to assess effectiveness or what assessment methods should be applied [8]. This situation emerges in part because the evaluation community, over the past decades, has focused on evaluating projects and programs, with little guidance provided for the assessment of institutions and networks [9]. Moreover, organizations and States, democratic or not, 


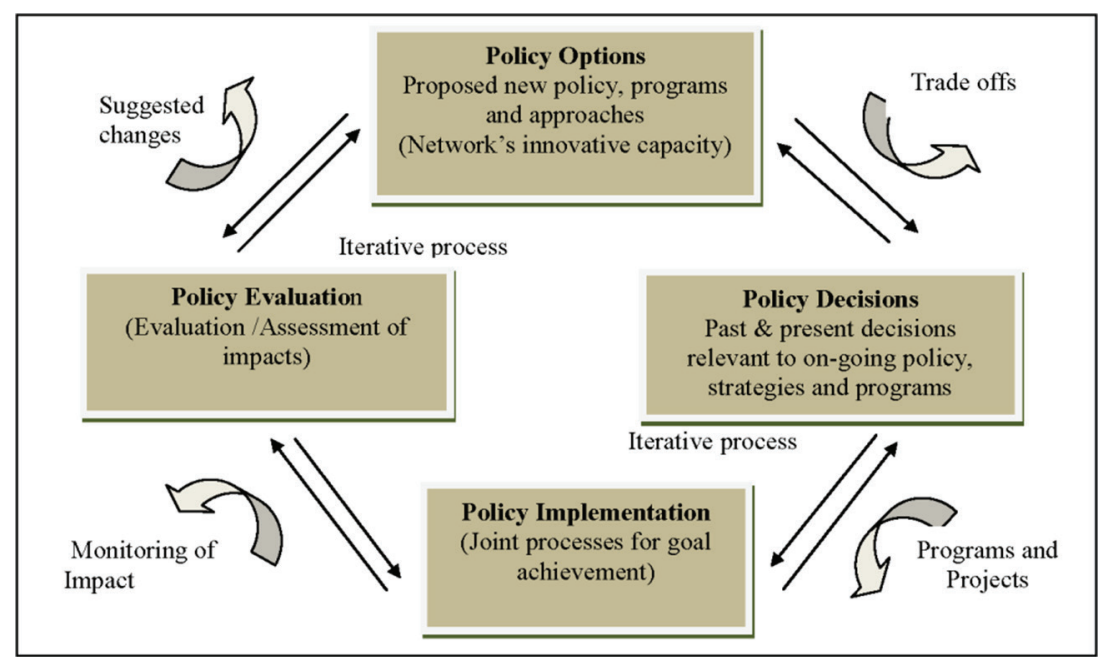

Figure 1: The policy analytical framework (PAF).

Note: For simplicity the framework is called PAF, but pragmatically it is a tool for the analysis of policy and related programs and projects. Source: Authors

dislike receiving unwelcome truths, thus administrative structures frequently undermined well-intentioned assessment exercises [10]. Thus, it should come as no surprise that the assessment of institutions as 'governance networks' is at a relatively early stage of development $[11,12]$. As a consequence, there is considerable ongoing debate among academics and public administrators concerning appropriate evaluation frameworks [13-15].

Despite the debates, we identified several useful directions. Literature on network theory suggests that instead of devising different sets of criteria for different stakeholders, it is better, as indicated by Sorensen and Torfing [16], to relate the measurement of performance of networks to the different phases of the policy process. This observation was the starting point for our approach; we elaborated performance indicators for each of the four stages of the policy cycle and applied them both to individual stakeholders and, via integration of the results, to the network as a whole. Additional considerations in evaluating the effectiveness of the WSS governance network included: Meyer [17] perspective that new ways of framing and addressing an issue, new learning processes and new visions are vital outputs of a network; and Turrini et al. [14] emphasis on the network's ability to reach stated goals, capacity for innovation and change, and its longer-term sustainability.

The overall approach to network governance defined, we still had the challenges of specifying what constituted the governance network for a specific territory and how to empirically assess its effectiveness. These tasks were tackled using a two phase design. The first phase identified the WSS governance network by detecting the critical stakeholders; the second phase made an approximation of governance network effectiveness through the assessment of network processes and outputs following the proposed four stage analytical framework (Fig. 1).

\subsection{Identification of the governance network}

To identify the critical stakeholders in the WSS network, we used a method developed by the World Bank's Urban Management Program: following specific issues and programs to 
establish the involvement of various stakeholders [18, 19]. Individual entities' strategies and actions were documented and the overall network was mapped. Those entities, which are identified as 'working in the network form of organization,' were then studied, as described below.

\subsection{The assessment of network effectiveness}

In the second research phase, the Policy Analytical Framework (PAF) was used to assess the governance network's outputs. At each of the four developmental-procedural stages of the PAF, an evaluation tool was applied (Table 1). This approach permitted an integrated assessment, one that considered the concrete outputs of the network as a whole, such as the number of water systems constructed, as well as less tangible elements such as visions, strategies and on-going processes $[17,20]$. The approach also generated valuable information about the network's structure, composition and linkages.

The PAF tool was given to the national and local institutions in the WSS governance network in the case study area. Representatives of each institution were asked to complete the form by responding to the following open-ended guide questions: (1) What relevant decisions have been taken? (2) What has been implemented to accomplish which goals? (3) What assessments have been made? (4) What new policy options have been suggested or adopted to strengthen goal achievement?

\subsection{Evaluation Criteria for the WSS governance network}

A great variety of performance indicators specific to the water and sanitation sector have been reported in the literature. Many of these standard indicators relate to specific programs and projects [2, 21-23]. Little work has been done in the overall assessment of WSS governance networks, perhaps because deep understanding of networks requires collection of data on multiple institutions, which can be time consuming and costly [24]. To evaluate the effectiveness of Tela's WSS network, customized performance indicators were needed.

Criteria for the selection of performance indicators included correspondence to one of the four steps of the PAF and relevance to the network's attainment of its stated long-term

Table 1: Policy analysis framework tool (to be completed via field assessment with stakeholders)

\section{Policy decisions}

Past \& present decisions relevant to on-going policy, $\quad$ Stakeholder(s) Comments strategies \& programs

\begin{tabular}{lll}
\hline $\begin{array}{l}\text { Implementation } \\
\text { Projects \& actions performed }\end{array}$ & Stakeholder(s) & Comments \\
\hline $\begin{array}{l}\text { Evaluation } \\
\text { Evaluations/assessments performed }\end{array}$ & Stakeholder(s) & Comments \\
\hline $\begin{array}{l}\text { Policy options } \\
\begin{array}{l}\text { Proposed new policy, programs, approaches \& } \\
\text { practices }\end{array}\end{array}$ & Stakeholder(s) & Comments \\
\hline
\end{tabular}


objectives. Performance indicators to assess the WSS governance network were specified for each stage of the policy process (Table 2). Twenty-three indicators were selected, covering important issues related directly to WSS delivery (e.g. water availability and quality) as well as to governance, such as coordination capacity, conflict resolution, and organizational culture. Four indicators refer to the policy decision step, six to implementation, six to assessment, and seven to new policy options. Data collected on the indicators provide a basis for assessing network performance vis-à-vis stated goals for both network outputs and processes.

Table 2: Performance indicators.

Policy decision indicators

1 A long-term engagement with the local $5 \quad$ Strengthening local sector institutions water sanitation sector

2 An institution/organization working towards the development of sustainable and cost-effective WSS systems

3 Coordination with other stakeholders of 7 Constructing WSS systems the network/number of links with other network partners

4 New WSS projects are including super- 8 vision and control methodology (e.g. ERSAPS/USCL, see Figure 2) providers tection
6 Strengthening water boards and service

8 Working toward micro-watershed pro-

9 Establishment and management of WSS information system

10 Participating in national or local forum for information exchange (e.g. RASHON, see Figure 2)

\begin{tabular}{|c|c|c|}
\hline \multicolumn{2}{|c|}{ Assessment Indicators } & New Policy Options Indicators \\
\hline 11 & $\begin{array}{l}\text { Supervision of the construction of new } \\
\text { WSS systems }\end{array}$ & $\begin{array}{l}17 \text { New approaches to WSS management } \\
\text { considering climate change }\end{array}$ \\
\hline 12 & $\begin{array}{l}\text { Assessments of program or project } \\
\text { implementation by funding organization }\end{array}$ & $\begin{array}{l}18 \text { Development of new financial } \\
\text { approaches for the WSS }\end{array}$ \\
\hline 13 & $\begin{array}{l}\text { External third-party assessments during } \\
\text { program development and at project } \\
\text { completion }\end{array}$ & $\begin{array}{l}19 \text { Advocacy towards strengthening of a } \\
\text { local WSS leader (Policy \& Strategy) } \\
\text { (e.g. COMAS, see Figure 2) }\end{array}$ \\
\hline 14 & $\begin{array}{l}\text { Ex-post assessment one year after } \\
\text { project completion }\end{array}$ & $\begin{array}{l}20 \text { Advocacy for strengthening local WSS } \\
\text { technical assistance partners (e.g. } \\
\text { SANAA, see Figure 2) }\end{array}$ \\
\hline 15 & $\begin{array}{l}\text { Assessment and/or supervision of exist- } \\
\text { ing WSS system (on-going process) }\end{array}$ & $\begin{array}{l}21 \text { Advocacy for the installation of } \\
\text { household micro-water meters }\end{array}$ \\
\hline 16 & $\begin{array}{l}\text { Assessments and control of quality of } \\
\text { water (on-going process) }\end{array}$ & 22 Addressing gender inequality \\
\hline
\end{tabular}


In addition, the research framework allowed investigation of the network's capacity for longer-term sustainability, coordination among members, resolution of conflict, development of linkages, spaces for discourse and meta-governance functions. Cultural factors facilitating or impeding network outputs and processes were also explored. Network theory literature identifies all these factors as crucial to governance effectiveness.

\section{EVALUATION WITH SPECIFIC PERFORMANCE INDICATORS}

Eight entities - indicated in grey on Figure 2 - were found to constitute the WSS network for Tela; they were asked to complete the questions listed in Table 1. Data were obtained for each stage of the policy framework via document review, semi-structured interviews (with key informants of government, bilateral and multilateral agencies, partner NGOs, communitybased organizations (CBOs), and water boards), and a three-week participatory observation in the case study area [25]. Illustrative findings per policy stage follow.

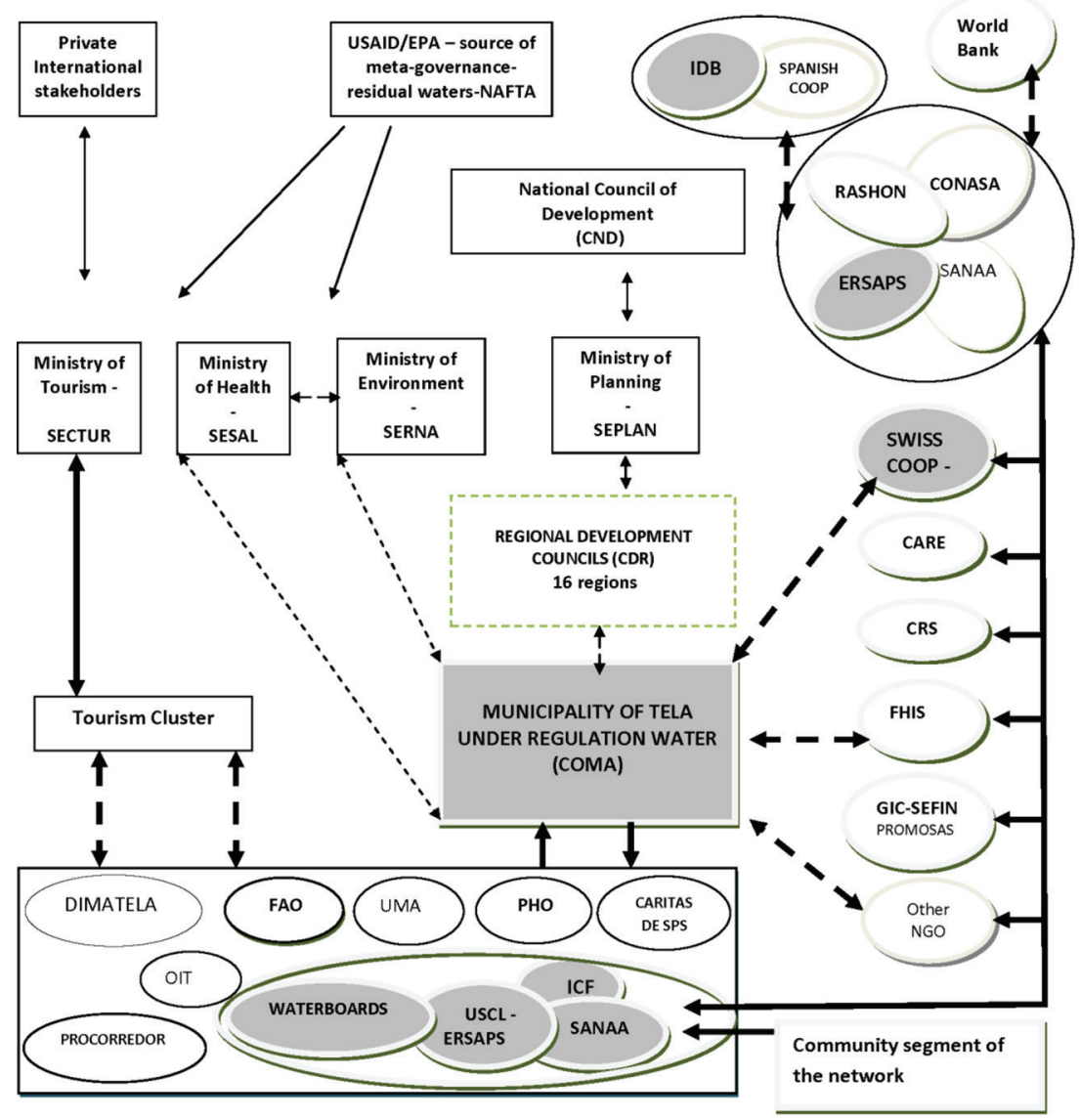

Figure 2: Conformation of the WSS governance network.

Note: The thickness of the arrow indicates strength of a linkage - An intermittent arrow indicates an occasional linkage. Source: authors 


\subsection{Policy decisions issues (Performance indicators 1-4)}

When combined, the data from the individual stakeholders suggest the network, as constituted, functions reasonably well with respect to policy decision issues. Policy decision indicators show that the network has a long-term engagement with the WSS sector and that it is oriented toward the development of sustainable cost-effective systems. Additionally, indicators reveal a good level of coordination, collaboration and trust among its local members, with a trio of stakeholders - the Unidad de Supervisión y Control Local, Servicio Autónomo Nacional de Acueductos y Alcantarillados, and Instituto Nacional de Conservación Forestal y Desarrollo Forestal, Areas Protegidas y Vida Silvestre (listed as USCL-SANAA-ICF in Figure 2) - operating effectively through informal agreements.

\subsection{Implementation issues (Performance indicators 5-10)}

With respect to implementation, evidence shows uneven performance, with the network performing well in some areas and not in others. Indicators show that three stakeholders are working to strengthen local institutions and the water boards. These actions have resulted in a network fully engaged in regulating 48 water boards with plans to expand coverage to other communities in the municipality. Some water boards are requesting to join the regulated system, reflecting recognition that the network strengthens those that participate. Moreover, the research found that the overall network is very active in micro-watershed protection, though some participants have failed to incorporate such protection into the design and implementation of their WSS programs.

\subsection{Monitoring and assessment issues (Performance indicators 11-16)}

As with the other performance areas, the network shows mixed results with respect to monitoring and evaluation. The international segment of the network consistently monitors progress and prepares project completion reports. However, the network does not seem to favor external third party assessment at project completion or appear concerned with ex-post assessment one year after project completion as only one stakeholder of the network is consistently applying these methods.

A unique characteristic of the community segment of the network is its interest in the assessment and control of the quality of water, a concern not expressed by ERSAPS, the national regulation authority. Local actions to improve water quality focus on the monitoring of micro-watersheds, chlorination of water reservoirs and water sampling for coliform count (although the effectiveness of the chlorination protocols appear questionable as some test results indicated high coliform counts even after chlorination).

\subsection{New policy issues (Performance indicators 17-23)}

The network shows mixed results with respect to policy options and new approaches. Important issues of local interest include: the signing of a formal agreement between water and health authorities to jointly supervise of water quality. Issues of climate change and new financial approaches generated little interest among local stakeholders. 


\section{EVALUATION WITH THE PAF CYCLE}

Water and sanitation for the municipality of Tela is managed through two approaches. The first focuses on improving conditions in the City of Tela, and the second focuses on improving conditions at the rural level.

The first approach places the responsibility for urban service provision exclusively in the hands of the Municipal Division of Waters of Tela (DIMATELA), which reports to the mayor. DIMATELA was not active in the WSS network. Observers said, 'DIMATELA resources are channeled to purchase products and services unrelated to water and sanitation, while many water problems remain unresolved due to lack of funding.'

The second approach of the Municipality of Tela focuses on managing water and sanitation in the rural areas. Empirical evidence from the research indicates that rural provision is managed through a WSS governance network working actively in the region. To assess effectiveness, analysis was done of its on-going processes and outputs at each of the four discrete stages of the PAF framework. Discussion of key aspects per stage follows.

The first stage of analysis, which refers to policy decisions, shows that the community segment of the network (Fig. 1) as a rule does not create, propose or implement new policies or suggest new approaches. It follows policies that are generated elsewhere. But exceptions exist: the community segment decided that the water supply of the water boards should be monitoring for coliform count and this constitutes an example of the community segment participating in decision making.

The second stage of analysis, which refers to implementation capabilities, indicates that the network is relatively active in overall program and project development. However, its construction of new water systems is at a very low level of activity (less than 10), although many communities need new and/or improved systems. The lack of a network member with water system construction capabilities partially accounts for low performance in this area, as does lack of dedicated funding. The research found that the network was addressing both constraints: inclusion of an experienced construction entity in the network and fresh funds made available by the Inter-American Development Bank (IDB) for new rural systems, of which at least six are being planned for the Tela region.

The third stage of the analysis relates to monitoring, evaluation and other forms of assessment. The network had 48 regulated water boards in 2012. Each board is supervised quarterly for adequacy of tariffs, frequency of service, volume of water supplied, system disinfection, water quality, and status of sanitation. Great care is taken in the monitoring and control of the finances of the water boards to the point that the culture of paying a monthly fee for water provision is now deeply rooted among the regulated water boards. Reports indicate that the average tariffs collected in the municipality of Tela is $28 \%$ over its operating costs, with a low level of arrears at the water board level [26]. This approach has improved the quality of life of the participating communities, and is a model of excellence within a country context that does not have a culture of supervision or regulation.

The fourth stage of the cycle, which refers to the network's contribution to the generation of new policies or processes, shows that the higher-level governance portion of the network played a major role in the enactment of the WSS framework law of 2003. This law resulted in significant advancement of the rural WSS agenda of the Municipality of Tela. Meanwhile, the community segment of the network has also been active, advocating for improved coordination with Public Health authorities - to help supervise water quality - and expanded protection of micro-watersheds up-stream of water reservoirs. 


\subsection{Linkages, meta-governance and culture issues of the WSS governance network}

It was determined that the Municipality of Tela has an active local WSS governance network composed of four stakeholders strictly working at the community level, with another four stakeholders operating at higher levels of governance. The three local entities (ICF, USCL and SANAA) and the water boards constitute the community segment of the network, and the Municipal Corporation (COMAS), the Swiss Cooperation, and the two meta-governors, ERSAPS and IDB, comprise the higher-level segment of the network (Fig. 2). The four members of the community segment have excellent horizontal linkages and operate very smoothly - intra-network conflicts are almost non-existent, possibly because of transparency and convivial relations among the members.

\subsection{Highlights of the WSS governance network}

Overall the network made significantly contributions to advancing the rural WSS agenda of the municipality of Tela, a development made possible because higher-level governance portions of the network is permanently engaged in policy and institutional development, and played a major role in the enactment of the new WSS framework law of 2003. It was then that the country embarked on the development of the water sector from a municipal perspective. This municipal focus greatly benefited the Municipality of Tela as it was one of the first to receive technical assistance and funds for capacity building of its water sector.

The high-level portion of the network has supported and continues to support institutions, organizations and networks in the Water and Sanitation sector in the country. In fact, the World Health Organization (WHO) identifies Honduras as one of the three Latin American countries that has most advanced in water and sanitation provision since the 1990s [27]. How was this advancement accomplished? The research suggests that the leadership of international development organizations engaged with water and sanitation was a pivotal factor. An unfortunate lack of Honduran state leadership for WSS [28] meant that, as our research shows, the WSS governance network of the Municipality of Tela turned to international stakeholders and ERSAP (Fig. 2) for meta-governance of the network.

Furthermore, the research points toward policy and organizational dynamics important to future water and sanitation decision-making. For instance, the research indicates that, overall, the Water and Sanitation country sector is steered by two meta-governors, namely the Inter-American Development Bank and the World Bank, with strong support provided by ERSAP and aid from other strategic institutions such as the Swiss Cooperation for Development (SCD). To improve the effectiveness of all the institutions and networks working in the water sector in the country, more support could be directed to local entities. Some are already active in the network and promoting WSS nationally: ERSAPS (the national regulatory institution for water supply and sanitation) is providing some WSS leadership nationally; and RASHON (Honduras Water and Sanitation Network), a public/private legally chartered institution, acts as a forum for information-sharing on water and sanitation issues in Honduras. Two national-level institutions, the National Committee of Water and Sanitation (CONASA) and National Autonomous Service of Water and Sewage (SANAA), were not considered members of the WSS governance network but could, if transformed, potentially be important stakeholders. Fieldwork completed in 2010-2012, revealed, for instance, that CONASA had conducted minimal work during a 10-year period, mainly because of the lack of leader- 
ship and ministerial support. Similarly, lack of resources accounted, at least partially, for SANAA's overall disengagement from its technical assistance responsibilities [28, 29].

\section{CONCLUSIONS AND SUGGESTIONS FOR FUTURE RESEARCH}

This research proposes and applies a new framework for the assessment of the effectiveness of Water and Sanitation Sector (WSS) governance networks in developing countries. The framework is grounded on the theoretical perspective that, rather than applying different criteria for each of the stakeholders, it is better to relate the overall performance of a network to the different phases of the policy process, [16]. The resulting approach, based on network theory, could improve water and sanitation provision while advancing knowledge in the emerging field of governance network assessment.

The proposed two-phase analytical method first identifies the WSS governance network, and then makes an approximation of effectiveness through the policy analysis framework (PAF), which evaluates effectiveness based on network outputs and on-going processes (Fig. 1). The framework, following leading network theories, relates the overall performance of the network to the different phases of the policy process [16]. Each of the four stages of the policy process is supported by the application of performance indicators custom-designed to assess the WSS governance network (Table 2). The chosen indicators not only cover a wide range of important water issues, such as quality and availability, but also important network aspects, such as coordination capacity, conflict resolution capacity, and culture.

The proposed PAF assessment methodology, with its related family of custom indicators, opens up many areas for future research [30]. Other WSS governance networks can be evaluated by applying or slightly modifying the 23 indicators designed for this research or, alternatively, the WSS network could be evaluated from other perspectives such as efficiency, relevance, financial viability, and gender participation, restructuring the indicators to suit. In addition, future research is not restricted to WSS governance networks. Based on the general applicability of the methodology, it can be replicated to assess networks operating in other sectors such as education, environment, green growth and food security, again incorporating a set of relevant performance indicators.

This new analytical framework for the assessment of the effectiveness of water and sanitation sector (WSS) governance networks is a simple and useful tool for informed decision making for those working to improve water and sanitation provision through network forms of organization, particularly for the benefit of communities or society at large. The investigation also advances governance network evaluation methodology.

\section{ACKNOWLEDGEMENTS}

This research was made possible thanks to the financial support of the FQRSC (Fonds de Recherche sur la Société et la Culture du Quebec), IDRC (International Development Research Center), the Association of AUCC/CIDA (Sustainable tourism project - Honduras) and the School of Urban Planning, McGill University, Montreal, Canada.

\section{REFERENCES}

[1] Gray, T. \& Stewart, A., International Library of African Studies: Governance of Water and Sanitation in Africa: Achieving Sustainable Development Through Partnerships, I.B. Tauris: London, GBRp. 110, 2009.

[2] White, H. \& Black, R., Targeting Development: Critical Perspectives on the Millennium Development Goals, Taylor \& Francis, 2003. 
[3] Parker, R., Berg, G., Sieburger, M. \& Heuser, S. (eds), Water and development: taking lessons from evaluation - Summary of discussions at the Berlin Conference. The Berlin Conference on Water and Development; 2010; Berlin: The Independent Evaluation Group of the World Bank (IEG) and the Evaluation Department of KfW Entwicklungsbank (development bank).

[4] Tesselaar, R. Engelbertink, J., Kemp, A.D. \& Jorritsma, H. (eds), From Infrastructure to Sustainable Impact: Policy Review of the Dutch Contribution to Drinking Water and Sanitation (1990-2011), The Hague, The Netherlands: Netherlands, Ministry of Foreign Affairs, Policy and Operations Review Department (IOB), 2012.

[5] Cotton, A., Adams, J. \& Shaw, D., Improving water supply and sanitation programme effectiveness: Lessons from WaterAid's outcome evaluation studies. Water and Environment Journal, 27, pp. 1-9, 2013. https://doi.org/10.1111/j.1747-6593.2012.00317.x

[6] Yin, RK., Case Study Research: Design and Methods -Third Edition - Applied Social Research Methods Volume 5, Leonard Bickman DJR, editor: Sage Publications, 2003.

[7] Albrecht, M., Elbe, J., Elbe, S. \& Meyer, W., Analyzing and evaluating regional governance networks: three challenges for applications. Evaluation, 20, pp. 58-74, 2014. https://doi.org/10.1177/1356389013518457

[8] Torfing, J. \& Sørensen, E., The European debate on governance networks: towards a new and viable paradigm? Policy and Society, 33, pp. 329-344, 2014. https://doi.org/10.1016/j.polsoc.2014.10.003

[9] Rojas, K. \& Lusthaus C., The evolution of institutional and organizational assessment. In G. Anderson (ed), Shaping International Evaluation, Montreal, 2010.

[10] Moran, M., Rein, M. \& Goodin RE., The public and its policies. The Oxford Handbook of Public Policy, Oxford University Press, 2006.

[11] Hertting, N. \& Vedung, E., Purposes and criteria in network governance evaluation: How far does standard evaluation vocabulary takes us? Evaluation, 18, pp. 27-46, 2012. https://doi.org/10.1177/1356389011431021

[12] Lusthaus, C., Garven, K. \& Grandi, S., Chapter four: evaluating partnerships in the not for profit sector. In Universalia, editor. Shaping International Evaluation, Universalia Management Group, 2010.

[13] Span, K., Luijkx, K., Schols, J. \& Schalk, R., The relationship between governance role and performance in local public interorganizational networks: A conceptual analysis. The American Review of Public Administration, 42(2), pp. 186-201, 2012. https://doi.org/10.1177/0275074011402193

[14] Turrini, A., Cristofoli, D., Frosini, F. \& Nasi, G., Network literatute about determinants of network effectiveness. Public Administration, 88(2), pp. 528-550, 2010. https://doi.org/10.1111/j.1467-9299.2009.01791.x

[15] Nance, E.B., Multistakeholder evaluation of condominial sewer services. American Journal of Evaluation, 26(4), pp. 480-500, 2005. https://doi.org/10.1177/1098214005281324

[16] Sorensen, E. \& Torfing, J., Making governance networks effective and democratic through metagovernance. Public Administration, 87, pp. 243-258, 2009. https://doi.org/10.1111/j.1467-9299.2009.01753.x

[17] Meyer, M.W., Rethinking Performance Measurement, Cambridge University Press, 2002.

[18] Brown, D. \& Mooleedhar, T., The response of public authorities to a local emergency: the Demera Road incident. Human Systems Management, 17, pp. 49-62, 1998. 
[19] Bartone, C., Bernstein, J. \& Leitman, J., Toward Environmental Strategies for Cities, Programme UM, editor, Washington: The World Bank, 1995.

[20] Wiek, A. \& Larson, K., Water, People, and sustainability-A systems framework for analyzing and assessing water governance regimes. Water Resources Management, 26(11), pp. 3153-3171, 2012. https://doi.org/10.1007/s11269-012-0065-6

[21] Water and Sanitation Program - Central American Region. Poverty and Sanitation - An analysis of the linkage between poverty and access to basic sanitation in Honduras, available at www.wsp.org, 2008.

[22] Gurria, A., IV. Governance: at the root of the problem, at the hearth of the solution. Water: Towards a Culture of Responsibility, University of New Hampshire Press, 2011.

[23] ERSAPS. Indicadores 2010 del Sector Agua y Saneamiento en Honduras, ERSAPS, 2010.

[24] Provan, K.G. \& Kenis, P., Modes of network governance: Structure, management, and effectiveness. Journal of Public Administration Research and Theory, 18, pp. 229-252, 2007.

https://doi.org/10.1093/jopart/mum015

[25] Jorgensen, D.L., Participant observation: A methodology for human studies - Applied Social Research Methods Series, Volume 15, Sage Publications, 1989.

[26] ERSAPS. Indicadores 2011 del sector Agua Potable y Saneamiento en Honduras. ERSAPS, 2011.

[27] Organización Mundial de la Salud. En 24 años, 17\% de latinoamericanos tienen acceso a agua potable y saneamiento, available at www.americaeconomia.com/politicasociedad/mundo/en-24-anos-17-mas-de-latinoamericanos-tienen-acceso-agua-potabley-saneamien (accessed 8 January 2017)

[28] Inter-American Development Bank. Informe de Terminacion de Projecto: Programa en Inversión en Agua Potable y Saneamiento HO0072, available at www.idbdocs.iadb.org/ wsdocs/getdocument.aspx?docnum=37318279 (accessed 8 January 2017)

[29] Gentes, I., Agua potable, saneamiento y calidad en Honduras: Desde una vision consensuada a la accion concertada, available at www.ersaps.hn/documentos/interes/ PAPSAC_Sintesis.pdf: Programa de Apoyo Presupuestario Sectorial en Agua y Calidad (PAPSAC), convenio de financiación no Reembolsable No. DCI-ALA/2011/22-863 de la Union Europea, 2014 (accessed 9 January 2017)

[30] Alvarado, R.E., Assessing the effectiveness of water and sanitation sector governance networks in developing countries: a policy analysis framework and its application to the governance network for the Municipality of Tela, Honduras, Ph D thesis, Mcgill University, 2015, available at http://digitool.library.mcgill.ca/R/TTJTQV5LC4T9YTJDMDT459C1KUBL LIDUH269AGKFGFPA9D4QQE-00476?func=collections-result\&collection_id=1575 